\title{
PREFACE TO FIRST EDITION
}

The idea for this book grew out of writing an article on terms implied in fact, the inspiration for which grew from a remark made to me by a very distinguished law professor. I had referred to the case of The Moorcock as one example of the flexibility of contract law. He dismissed this, airily saying that a Law Lord had told him that he (the Law Lord) knew that counsel were scraping the barrel as soon as they cited The Moorcock. I was not terribly pleased to have my argument dismissed on the basis of what one judge, however distinguished, had remarked to a professor, however distinguished, perhaps over a glass of port or a gin and tonic in the pension room of an Inn of Court (as I imagine the conversation taking place). This irritation led to an article about terms implied in fact, and the interest that stirred in me ultimately resulted in this book. That article was published as 'Implied Terms in English Contract Law: The Long Voyage of The Moorcock' (2009) 38 Common Law World Review 56, and the substance of it is reproduced in Chapter 7 of this book.

Implication of terms is, to my mind, one of the most important weapons in the armoury of lawyerly and judicial technique. A thorough knowledge by the practitioner of what terms are and are not likely to be implied will permit him or her to advise a client what is likely to happen if anything goes wrong in the absence of an express clause providing for that event, and perhaps guide the client away from unnecessary negotiations, conflict, concessions payment of price for terms that are unlikely ever to be needed (since relatively few contracts ever result in breakdown and the causes of breakdowns are so multifarious that nearly all contractual terms are in fact completely redundant) and where the client would be perfectly content with the effect of the likely implied term. As a judicial technique, it permits the court to 'discover' an interpretation of a contract more clearly aligned to its view on any particular occasion of what is common sense or fair, without ever having to admit to doing such a heinous thing. For parties who are entirely conscious of the terms usually implied in their trade, it saves time and ink. Yet, in spite of all this, the textbooks, student and practitioner ones alike, skip rather briefly over this subject and there is no current specialist volume on the subject of implied terms in English law. It is this deficiency which this volume is intended to supply. I hope that it will be of assistance to the practitioner as well as being of interest to the academic and student. To this end, I have emphasized the task of stating the law as best I can, with detailed and critical discussion of the leading cases, focussing rather less on the purely theoretical aspects, though I hope it will not be felt that I have unduly neglected these.

I would like to acknowledge with gratitude the considerable assistance furnished to me by Donna Neill, a former student of mine, now a research student at Bristol University. Donna provided many, many hours of painstaking research assistance 
which tremendously speeded the process of researching and writing this book. Another former student, Emma Smith, also deserves my gratitude for her work in gathering cases related to The Moorcock in preparation for the work on terms implied in fact. I have also benefitted from research leave in Lent Term 2009 from Lancaster University, which helped enormously.

I have endeavoured to state the law as at 1st May 2010. 